\title{
Awareness and knowledge among internal medicine house-staff for dose adjustment of commonly used medications in patients with CKD
}

Sikander Surana ${ }^{1}$, Neeru Kumar', Amita Vasudeva ${ }^{1}$, Gulvahid Shaikh¹, Kenar D. Jhaveri ${ }^{2}$,Hitesh Shah², Deepa Malieckal ${ }^{2}$, Joshua Fogel ${ }^{3}$, Gurwinder Sidhu $^{1}$ and Sofia Rubinstein ${ }^{1 *}$ (D)

\begin{abstract}
Background: Drug dosing errors result in adverse patient outcomes and are more common in patients with chronic kidney disease (CKD). As internists treat the majority of patients with CKD, we study if Internal Medicine house-staff have awareness and knowledge about the correct dosage of commonly used medications for those with CKD.

Methods: A cross-sectional survey was performed and included 341 participants. The outcomes were the awareness of whether a medication needs dose adjustment in patients with CKD and whether there was knowledge for the level of glomerular filtration rate (GFR) a medication needs to be adjusted.

Results: The overall pattern for all post-graduate year (PGY) groups in all medication classes was a lack of awareness and knowledge. For awareness, there were statistically significant increased mean differences for PGY2 and PGY3 as compared to PGY1 for allergy, endocrine, gastrointestinal, and rheumatologic medication classes but not for analgesic, cardiovascular, and neuropsychotropic medication classes. For knowledge, there were statistically significant increased mean differences for PGY2 and PGY3 as compared to PGY1 for allergy, cardiovascular, endocrine, and gastrointestinal, medication classes but not for analgesic, neuropsychotropic, and rheumatologic medication classes.
\end{abstract}

Conclusions: Internal Medicine house-staff across all levels of training demonstrated poor awareness and knowledge for many medication classes in CKD patients. Internal Medicine house-staff should receive more nephrology exposure and formal didactic educational training during residency to better manage complex treatment regimens and prevent medication dosing errors.

Keywords: Chronic kidney disease, Medication dose adjustment, Dosing errors, Internal medicine, Internship and residency

\section{Background}

Chronic kidney disease (CKD) is an important health problem with a rising incidence and prevalence in the general United States (US) population [1, 2]. Over the past two decades, there has been a $10-20 \%$ increase in incidence and prevalence of CKD stages $3-5$ [3, 4]. CKD prevalence in the US general population is $13.6 \%$ [5].

\footnotetext{
*Correspondence: srubinst@numc.edu

${ }^{1}$ Nephrology Division, Department of Medicine, Nassau University Medical Center, 2201 Hempstead Turnpike, Box 49, East Meadow, NY 11554, USA

Full list of author information is available at the end of the article
}

This prevalence is even higher in patients with prediabetes (18\%), diabetes (40-42\%) and the elderly (23$58 \%$ ) [6-10]. The elderly are a growing population with demographic models projecting their number to increase to about 1 in 5 people by the year 2030 [11].

The steep increase in the prevalence of CKD among the elderly might be partly due to related co-morbidities such as cardiovascular diseases, diabetes or hypertension [12]. Further, patients with CKD are at increased risk for cardiovascular and non-cardiovascular diseases, including infection and malignancy $[13,14]$. With the increase 
in these co-morbid conditions with increasing age, elderly patients receive a large number of medications $[15,16]$. These multiple drugs and complex regimens to achieve treatment goals for management of both CKD complications and various co-morbidities, put the elderly at a higher risk for drug related problems [15, 17].

Polypharmacy is highly prevalent and dosing error is one of the most important drug related problems in the elderly [18-23]. In a study of elderly patients in the US, over half reported the combined use of 5 or more prescription/non-prescription medications or dietary supplements [24]. In a similar study of elderly patients from Austria, the mean number of drugs taken was 7.5 with $58.4 \%$ of the elderly patients fulfilling their criteria for polypharmacy of more than 6 drugs [25]. Polypharmacy appears to be amplified in patients with CKD with one study reporting a mean of 8 medications in elderly patients with CKD stages 3 through 5 [26].

Many medications require dose adjustment in patients with CKD. Incorrect drug dosing was reported in 23.4\% of patients, the majority of whom had renal impairment [25]. A review that assessed clinicians' adherence to dosing guidelines for CKD patients reported nonadherence rates ranging from 19 to $67 \%$ [19]. A recent study further highlights this problem and reports that of the total 1464 antibiotic prescriptions filled for patients with CKD, 970 (66.3\%) were for doses in excess of recommended guidelines [27]. Drug dosing errors can result in adverse effects, poor patient outcomes, and contribute to excess financial expenditures [28]. Adverse drug events are one of the top 7 leading causes of death in US and Canada [28-31]. In the US, annually more than 200,000 people die and another 2.2 million people are injured because of medication related problems [29, 32]. The cost associated with medication-related problems is estimated at over $\$ 2$ billion per year in the US [33].

Due to a growing CKD population coupled with the often limited number of nephrologists and late referrals, the majority of CKD patients receive their ambulatory care from primary care physicians [16, 34]. In addition, patients with CKD are at increased risk for hospitalization where they are cared for by generalists $[3,35,36]$. It is important to determine if Internal Medicine (IM) house-staff are obtaining the knowledge necessary to correctly dose medications in a CKD population. To the best of our knowledge this has not been studied worldwide. We study awareness and knowledge among IM house-staff of dosage adjustment for commonly used medications across different medication classes in patients with CKD.

\section{Methods}

\section{Participants and setting}

We conducted a cross sectional survey to assess awareness and knowledge among 341 IM house-staff for dosage adjustment of commonly used medications across different medication classes in patients with CKD. The study was performed at six academic hospitals located in New York City and its suburbs. IM housestaff across all levels of training were surveyed in their fourth through sixth month of their training year.

\section{Variables}

The following demographic information was collected: age (years), sex, medical school (graduate of American or International medical school), and level of training (post-graduate year (PGY)1, PGY2, PGY3 or greater). Personal/family history of kidney disease (personal history and/or history of kidney problems among spouse or children, and presence or absence of kidney problems in any first-degree relatives) was obtained. A renal training score (ranging from 0 to 3 for each affirmative response) consisted of the following: prior nephrology training or renal electives in medical school or residency, regular attendance at renal clinic (defined as 10 times or more during training), and interest in nephrology for further training.

A list of 26 commonly used medications was compiled representing 7 different medication classes: allergy (diphenhydramine, loratadine, montelukast), analgesic (acetaminophen, ibuprofen, meperedine, tramadol), cardiovascular (amlodipine, atenolol, carvedilol, digoxin, enalapril, hydralazine, simvastatin), endocrine (glipizide, pioglitazone, sitagliptin), gastrointestinal (famotidine, pantoprazole), neuropsychotropic (alprazolam, gabapentin, haloperidol, levetiracetam, paroxetine), and rheumatologic (allopurinol, colchicine). We offered the following possible responses to each medication: a) does not need dose adjustment, b) needs dose adjustment at glomerular filtration rate $($ GFR $)<90 \mathrm{ml} / \mathrm{min}, \mathrm{c})$ needs dose adjustment at GFR $<60 \mathrm{ml} / \mathrm{min}$, d) needs dose adjustment at $\mathrm{GFR}<30 \mathrm{ml} / \mathrm{min}$, and e) I don't know.

\section{Outcome variables}

One outcome was to assess the awareness among house-staff whether a given medication needed dose adjustment in patients with impaired renal function ('medication dose needs adjustment' awareness). The other outcome was to assess the knowledge among house-staff whether they knew at what level of GFR a given medication needs to be adjusted ('medication dose adjustment at appropriate GFR level' knowledge) according to published medication dosing guidelines in CKD [37, 38]. A score of 'one' was assigned for every correct response to a medication. A total score was calculated for each medication class and also for all medications ('overall medication score'). 


\section{Statistical analyses}

Descriptive statistics of either mean and standard deviation or frequency and percentage were used to describe the variables. The independent variable was postgraduate year (PGY). One outcome was correct 'medication dose needs adjustment' awareness and the other was correct 'medication dose adjustment at appropriate GFR level' knowledge. Analysis of variance (ANOVA) was conducted for total of all medications and also seven different medication classes. For the analyses with statistically significant differences, least significant difference (LSD) post-hoc analyses and analysis of covariance (ANCOVA) were conducted. The covariates included in the ANCOVA analyses were age, sex, medical school location, personal/family history of kidney disease, and renal training score. For the outcome variable with a skewed distribution, non-parametric analyses of the Kruskal Wallis test instead of ANOVA, Mann-Whitney tests instead of LSD post-hoc tests, and rank ANCOVA (Quade's test) instead of ANCOVA were performed. A total score of all medications was calculated for all the 341 participants counting only the correct responses. Also, to allow for including the greatest number of participants in the ANCOVA analyses, the 34 individuals who omitted age were imputed with the mean sample age. SPSS Version 22 was used for all analyses. All $p$ values were two-sided.

\section{Results}

Table 1 shows the descriptive statistics of the sample. Mean age was almost 30 years. Men were slightly more

Table 1 Descriptive Statistics of a Sample of 341 Internal Medicine Residents

\begin{tabular}{llccc}
\hline Variables & Frequency & Percent & Mean & SD \\
\hline Age (years) & & & 29.2 & 2.95 \\
Sex & 158 & 46.3 & & \\
$\quad$ Women & 182 & 53.4 & & \\
$\quad$ Men & 1 & 0.3 & & \\
$\quad$ Missing & & & & \\
School & 165 & 48.4 & \\
$\quad$ United States & 167 & 49.0 & & \\
$\quad$ International & 9 & 2.6 & & \\
$\quad$ Missing & & & & \\
Training & 158 & 46.3 & & \\
$\quad$ PGY1 & 101 & 29.6 & & \\
PGY2 & 82 & 24.0 & & \\
$\quad$ PGY3 and greater & 36 & 10.6 & & \\
Kidney disease history (yes) & & & & \\
Renal training score & & &
\end{tabular}

Note: $P G Y$ post-graduate year, $S D$ standard deviation than women. Approximately equal numbers received their medical school training in the US and internationally. Almost half surveyed comprised of PGY1, with the PGY2 and PGY3 comprising approximately one-quarter for each group. Slightly more than one-tenth had a personal/family history of kidney disease. Mean renal training score was below 1 on a scale with a total possible score of 3.

Table 2 shows comparisons for PGY groups for total scores for correct 'medication dose needs adjustment' awareness for different medication classes in CKD. ANOVA showed statistically significant mean differences for the PGY groups for total score of all medications, and also allergy, endocrine, gastrointestinal, and rheumatologic medication classes. These results were maintained in ANCOVA analyses adjusting for the relevant covariates. LSD post-hoc analyses showed that PGY2 had significantly greater mean scores than PGY1 for total score of all medications $(p=0.01)$, and also for allergy $(p=0.03)$, endocrine $(p=0.001)$, gastrointestinal $(p=0.004)$ and rheumatologic $(p<0.001)$ medication classes. LSD post-hoc analyses showed that PGY3 had significantly greater mean scores than PGY1for total score of all medications $(p<0.001)$, and also allergy $(p=$ $0.001)$, endocrine $(p<0.001)$, gastrointestinal $(p<0.001)$, and rheumatologic $(p<0.001)$ medication classes. Also, LSD post-hoc analyses for endocrine showed that PGY3 had significantly greater mean scores than PGY2 $(p=$ $0.01)$. There were no statistically significant mean differences for PGY groups for analgesic, cardiovascular, and neuropsychotropic medication classes. As can be seen by the mean scores, there was an overall pattern for all PGY groups in all medication classes except for rheumatologic where there was lack of correct knowledge. For rheumatologic medication class, PGY3 had 90.0\% 'completely correct' (correct response for all the medications in a given class), PGY2 had $76.8 \%$ 'completely correct', and PGY1 had 55.3\% 'completely correct' responses. An analysis of the 6 remaining medication classes showed that the highest percentage of 'completely correct' response for any particular medication class for any of the PGY groups was $17.1 \%$ for gastrointestinal (Fig. 1). For total score of all medications, no one scored 26/26 correct. Those who scored 20 or greater correct were 1 participant who scored 20/26 (0.3\%) correct and 2 participants who scored $25 / 26$ correct $(0.6 \%)$.

Table 3 shows comparisons for PGY groups for total scores for correct 'medication dose adjustment at appropriate GFR level' knowledge for different medication classes in CKD. ANOVA analyses showed statistically significant mean differences for the PGY groups for total score of all medications, and also allergy, cardiovascular, and gastrointestinal medication classes. The Kruskal Wallis test showed statistically significant mean 
Table 2 Comparisons for total scores of correct 'medication dose needs adjustment' awareness for different medication classes

\begin{tabular}{|c|c|c|c|c|c|c|c|}
\hline Variable & $\begin{array}{l}\text { Possible } \\
\text { Total Score }\end{array}$ & $\begin{array}{l}\text { PGY1 } \\
M(S D)\end{array}$ & $\begin{array}{l}\text { PGY2 } \\
M(S D)\end{array}$ & $\begin{array}{l}\text { PGY3 } \\
M(S D)\end{array}$ & $\begin{array}{l}\text { ANOVA } \\
p \text {-value }\end{array}$ & $\begin{array}{l}\text { ANCOVA } \\
p \text {-value }\end{array}$ & Post-hoc \\
\hline Allergy & 3 & $1.3(0.85)$ & $1.6(0.71)$ & $1.7(0.59)$ & 0.003 & 0.046 & $\begin{array}{l}P G Y 2>P G Y 1 \\
P G Y 3>P G Y 1\end{array}$ \\
\hline Analgesic & 4 & $1.3(1.03)$ & $1.1(0.90)$ & $1.4(0.91)$ & 0.19 & - & - \\
\hline Cardiovascular & 7 & $3.4(1.36)$ & $3.6(1.09)$ & $3.6(0.93)$ & 0.27 & - & - \\
\hline Endocrine & 3 & $1.1(0.86)$ & $1.5(0.76)$ & $1.8(0.67)$ & $<0.001$ & $<0.001$ & $\begin{array}{l}P G Y 2>P G Y 1 \\
P G Y 3>P G Y 1 \\
P G Y 3>P G Y 2\end{array}$ \\
\hline Gastrointestinal & 2 & $0.8(0.56)$ & $1.0(0.52)$ & $1.0(0.54)$ & $<0.001$ & 0.001 & $\begin{array}{l}P G Y 2>P G Y 1 \\
P G Y 3>P G Y 1\end{array}$ \\
\hline Neuropsychotropic & 5 & $2.1(1.28)$ & $2.2(1.00)$ & $2.2(0.97)$ & 0.79 & - & - \\
\hline Rheumatologic & 2 & $1.4(0.78)$ & $1.7(0.55)$ & $1.9(0.48)$ & $<0.001$ & $<0.001$ & $\begin{array}{l}\text { PGY2>PGY1 } \\
\text { PGY3>PGY }\end{array}$ \\
\hline Overall medication score & 26 & $11.2(4.31)$ & $12.4(3.28)$ & $13.3(2.10)$ & $<0.001$ & 0.002 & $\begin{array}{l}\mathrm{PGY} 2>\mathrm{PGY} \\
\mathrm{PGY} 3>\mathrm{PGY}\end{array}$ \\
\hline
\end{tabular}

Note: $M$ mean, $S D$ standard deviation, $P G Y$ post-graduate year, $A N O V A$ analysis of variance, $A N C O V A$ analysis of covariance. Sample sizes slightly vary due to omissions by participants

differences for endocrine medication class. These results were maintained in ANCOVA analyses after adjusting for the relevant covariates. LSD post-hoc analyses (or Mann Whitney tests for endocrine) showed that PGY2 had significantly greater mean scores than PGY1 for total score of all medications $(p<0.001)$, and also for allergy $(p=0.001)$, cardiovascular $(p=0.01)$, endocrine $(p=0.02)$, and gastrointestinal $(p=0.003)$ medication classes. LSD post-hoc analyses showed that PGY3 had significantly greater mean scores than PGY1 for total score of all medications $(p<0.001)$, and also for allergy $(p<0.001)$, cardiovascular $(p=0.004)$, endocrine $(p<$ $0.001)$, and gastrointestinal $(p=0.001)$ medication classes. There were no statistically significant mean differences for PGY groups for analgesic and neuropsychotropic medication classes, while rheumatologic medication class approached statistical significance for an overall statistical difference between the PGY groups. As can be seen by the mean scores, there was an overall pattern for all PGY groups in all medication classes where there was lack of correct knowledge. An analysis of the 7 different medication classes showed that the highest percentage of 'completely correct' response for any particular medication class for any of the PGY groups was $16.3 \%$ for rheumatologic medications (Fig. 2). For total score of all medications, no one scored 26/26

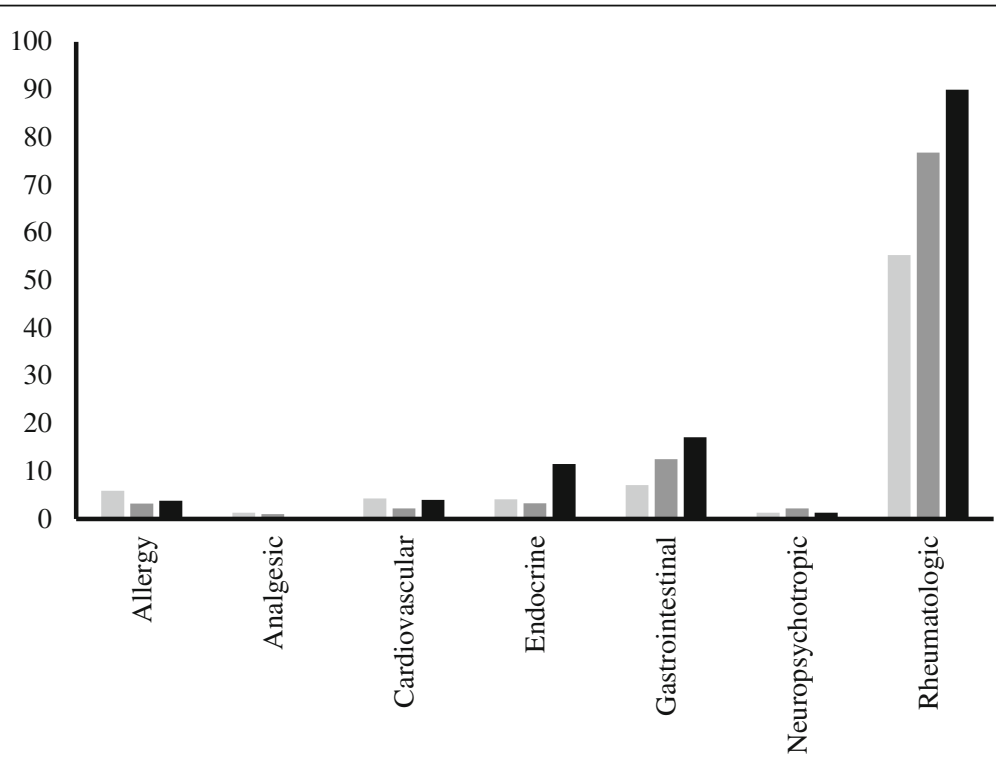

PGY1 $\square$ PGY2 $\square$ PGY3

Fig. 1 'Medication dose needs adjustment' awareness. Percent 'completely correct' responses by PGY groups 
Table 3 Comparisons for total scores of correct 'medication dose adjustment at appropriate GFR level' knowledge

\begin{tabular}{|c|c|c|c|c|c|c|c|}
\hline Variable & Possible Total Score & $\begin{array}{l}\text { PGY1 } \\
M(S D)\end{array}$ & $\begin{array}{l}\text { PGY2 } \\
M(S D)\end{array}$ & $\begin{array}{l}\text { PGY3 } \\
M(S D)\end{array}$ & $\begin{array}{l}\text { ANOVA or Kruskal Wallis } \\
p \text {-value }\end{array}$ & $\begin{array}{l}\text { ANCOVA } \\
p \text {-value }\end{array}$ & Post-hoc \\
\hline Allergy & 3 & $1.2(0.81)$ & $1.5(0.71)$ & $1.6(0.57)$ & $<0.001$ & 0.001 & $\begin{array}{l}\text { PGY2>PGY1 } \\
\text { PGY3>PGY1 }\end{array}$ \\
\hline Analgesic & 4 & $0.5(0.69)$ & $0.6(0.77)$ & $0.7(0.66)$ & 0.25 & - & - \\
\hline Cardiovascular & 7 & $2.1(1.06)$ & $2.4(0.99)$ & $2.5(0.84)$ & 0.004 & 0.03 & $\begin{array}{l}\text { PGY2>PGY1 } \\
P G Y 3>P G Y 1\end{array}$ \\
\hline Endocrine & 3 & $0.7(0.76)$ & $0.9(0.79)$ & $1.1(0.87)$ & 0.001 & 0.001 & $\begin{array}{l}\text { PGY2>PGY1 } \\
\text { PGY3>PGY1 }\end{array}$ \\
\hline Gastrointestinal & 2 & $0.7(0.55)$ & $0.9(0.50)$ & $0.9(0.45)$ & 0.001 & 0.002 & $\begin{array}{l}P G Y 2>P G Y 1 \\
P G Y 3>P G Y 1\end{array}$ \\
\hline Neuropsychotropic & 5 & $1.4(0.95)$ & $1.6(0.95)$ & $1.5(0.89)$ & 0.34 & - & - \\
\hline Rheumatologic & 2 & $0.4(0.62)$ & $0.5(0.73)$ & $0.6(0.76)$ & 0.054 & - & - \\
\hline Overall medication score & 26 & $6.8(3.09)$ & $8.3(2.91)$ & $8.8(2.02)$ & $<0.001$ & $<0.001$ & $\begin{array}{l}P G Y 2>P G Y 1 \\
P G Y 3>P G Y 1\end{array}$ \\
\hline
\end{tabular}

Note: $M$ mean, SD standard deviation, $P G Y$ post-graduate year, ANOVA analysis of variance, ANCOVA analysis of covariance. Sample sizes slightly vary due to omissions by participants. Endocrine, pain, and rheumatologic had skewed distributions and non-parametric analyses of the Kruskall Wallis test were performed instead of ANOVA. For endocrine, the Mann-Whitney test was performed instead of LSD post-hoc tests and rank ANCOVA (Quade's test) was performed instead of ANCOVA

correct. Those who scored 20 or greater correct were 1 participant who scored 21/26 (0.3\%) correct and 1 participant who scored $25 / 26$ correct $(0.3 \%)$.

\section{Discussion}

Our results showed that for analysis of 'medication dose needs adjustment' awareness there were statistically significant mean differences for total score of all medications, and also for allergy, endocrine, gastrointestinal and rheumatologic medication classes among the PGY groups with a consistent pattern of improved awareness for PGY2 than PGY1 and also for PGY3 than PGY1. Further, for endocrine medication class, there was statistically significant improved awareness for PGY3 than PGY2. There were no statistically significant mean differences among PGY groups for analgesic, cardiovascular and neuropsychotropic medication classes. For the analysis of the 'medication dose adjustment at appropriate GFR level' knowledge, there were statistically significant mean differences for total score of all medications, and also for allergy, cardiovascular, endocrine and gastrointestinal medication classes among the PGY groups with a consistent pattern of improved knowledge for PGY2 than PGY1 and also for PGY3 than PGY1. There were no statistically significant mean differences among PGY groups for analgesic, neuropsychotropic, and rheumatologic medication classes.

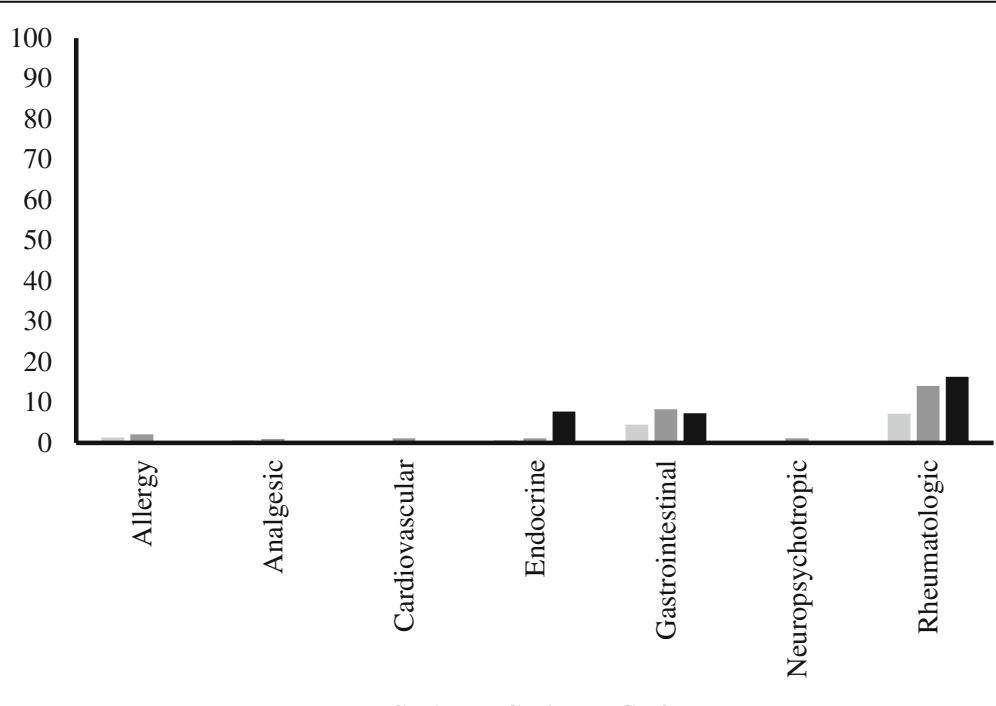

PGY1 $\square$ PGY2 —PGY3

Fig. 2 'Medication dose adjustment at appropriate GFR level' knowledge. Percent 'completely correct' responses by PGY groups 
There was a consistent pattern of improvement in prescribing for allergy, endocrine and gastrointestinal medication classes and also for the 'overall medication score' with increased level of training. At the statistically significant level, both PGY2 and PGY3 demonstrated better awareness for 'medication dose needs adjustment' and better knowledge for 'medication dose adjustment at appropriate GFR level' as compared to PGY1. There were no statistical differences between PGY2 and PGY3 for these medication classes except for endocrine medication class for the 'medication dose needs adjustment' awareness. For 'overall medication score', allergy and gastrointestinal medication classes, our data trended towards a better PGY3 score compared to PGY2, but this was not statistically significant. Medical knowledge is expected to improve as residents advance through various levels of training. The new Accreditation Council for Graduate Medical Education (ACGME) accreditation tool of 'milestones' is based on a similar principle that focuses on continuous improvement in graduate medical education, including the competency of medical knowledge [39]. As maintained by educational milestones, residents are expected to demonstrate growth in their medical knowledge at established intervals as they progress through training [39]. Our results are similar in that increased level of training conferred greater knowledge from PGY1 to PGY2 and PGY3. However, even with this greater knowledge for both PGY2 and PGY3, there was still overall poor correct knowledge for these medication classes.

There was no significant improvement in prescribing pattern for analgesic and neuropsychotropic medication classes for both 'medication dose needs adjustment' awareness and 'medication dose adjustment at appropriate GFR level' knowledge. In addition, the overwhelming majority had incorrect knowledge across all levels of training. One possibility may be due to the limited exposure and infrequent prescribing of these medications by IM house-staff. Typically in academic settings, specialists (psychiatrists and neurologists) are involved with prescribing and initiating these medications. Another possibility is that some of these medications are controlled substances and may not be routinely prescribed by IM house-staff. This limited experience among IM house-staff for some of these medications may contribute to the overall poor scores for these medication classes. Outside of academic settings, generalists prescribe the majority (59 to $85 \%$ ) of psychotropic medications in the US [40, 41]. However, studies report suboptimal dosing and duration with a lack of concordance between psychiatric diagnoses and prescribed psychotropic medications among generalists [42-44]. This has resulted in recommendations for graduate medical education programs to place greater emphasis on fundamental prescribing practices for psychotropic drugs [45-48]. Despite these recommendations, our results demonstrate poor knowledge about these medications among housestaff. With generalists responsible for the majority of these prescriptions, it is important that IM house-staff are aware of and adhere to dosing guidelines.

There was no statistical significance between the PGY levels for the 'medication dose needs adjustment' awareness for cardiovascular medication class, although the mean scores for PGY2 and PGY3 were greater than PGY1. For 'medication dose adjustment at appropriate GFR level' knowledge, PGY2 and PGY3 demonstrated statistically significant greater knowledge as compared to PGY1. Although PGY3 had a better score compared to PGY2, this was not statistically significant. However, even with this greater knowledge for PGY2 and PGY3 as compared to PGY1, mean scores indicated incorrect knowledge for more than half of the medications (i.e., at least 4.5 of 7 medications not correct). These results are surprising for the cardiovascular medication class. Cardiovascular disease is the second most common cause of hospitalizations in people over 65 years of age and is the leading cause of morbidity and mortality in the US accounting for almost 600,000 deaths in 2011 [49, 50]. IM house-staff receive vast exposure to cardiovascular disease through various cardiology rotations (including cardiac care unit, telemetry, cardiology consults, and cardiology clinics) in addition to treating numerous patients on medical floors and continuity clinics during residency. Furthermore, all IM house-staff are required to comply with'Centers for Medicare and Medicaid Services' guidelines for inpatient (acute myocardial infarction and congestive heart failure) and outpatient (acute myocardial infarction and chest pain) cardiovascular core measures during all patient encounters [51]. One possible reason for poor knowledge may be due to the mild adverse effects associated with an extra dose of most anti-hypertensive/cardiovascular medications. In a study of young children with unintentional, single drug exposure to commonly used antihypertensive medications (metoprolol, bisoprolol, ramipril, enalapril, lisinopril, captopril, candesartan, valsartan, amlodipine, and verapamil), only mild symptoms occurred [52]. On the contrary, certain medications like digoxin can cause serious adverse events with a single extra/higher dose in patients with renal impairment. In our responses for digoxin, overwhelming majority $(78.9 \%)$ of the house-staff were more cognizant that this medication needs to be adjusted in CKD.

There was a statistically significant mean difference between various PGY levels for the 'medication dose needs adjustment' awareness for rheumatologic medication class with PGY2 and PGY3 demonstrating better awareness as compared to PGY1. There were no 
statistical significant differences between PGY2 and PGY3, although PGY3 had higher mean scores. However, for the 'medication dose adjustment at appropriate GFR level' knowledge, we only found increased knowledge approaching significance among the PGY groups with mean scores improving as house-staff advanced through training. Interestingly, rheumatologic medication class had the highest percentage of correct responses as compared to all other medication classes. It is likely that the harmful side effect/adverse reaction profile of these medications contributes to better awareness and knowledge. A recent review of the safety and efficacy of allopurinol in CKD suggests that incidence of allopurinol hypersensitivity syndrome and other adverse effects like Stevens-Johnson syndrome can occur with a higher frequency in patients with impaired renal function [53]. Similarly, colchicine toxicity is more common among those with renal impairment and can be fatal [54-56].

Our sample data is fairly representative of the overall IM house-staff across the US. In the 2012-2013 academic year, there were 23,597 IM house-staff across all levels of training in the US [57]. The average age in our study was 29.2 years with $46.3 \%$ female house-staff. This is consistent with the US national average age of 29.4 years for IM house-staff with approximately $44 \%$ female house-staff [57]. The ACGME reports that there were $43.9 \%$ of international medical graduates (IMGs) in New York across all medical specialties as compared to $26.8 \%$ nationally [57]. Our sample had a similar percentage of IMGs as compared to the percentage of IMGs in New York of $49 \%$. Our distribution of house-staff based on level of training is also consistent with the national US statistics: 46.3 versus $43.0 \%$ for PGY1, 29.6 versus 29.0\% for PGY2, and 24.0 versus $28.0 \%$ for PGY3 (our sample versus US national average respectively) [57].

Our study has several limitations. First, the study was limited to the metropolitan area of New York. Although our sample was comparable in demographics to the total IM house-staff across the US, there may be a difference in patterns of training in different states. Second, the number of medications in each class was different. Third, the medications were selected based on our perception of what was being commonly prescribed. Fourth, we did not allow participants to use any automated support such as mobile- or computer-based devices for guidance in adjusting prescription dose. Although in clinical practice physicians have the opportunities to use these tools, our study is relevant as in clinical practice physicians are pressed for time and commonly do not utilize these tools [58], particularly if they are not even aware if a particular medication needs dose adjustment in CKD. Therefore it's important to have understanding of resident physician awareness and knowledge.

\section{Conclusions}

House-staff across all levels of training demonstrated poor awareness and knowledge of individualizing therapy based on patient's renal function. Poor knowledge of renal dosing rules and lack of medication information have been identified as major causes of prescribing errors $[59,60]$. Even with the use of electronic drug prescribing systems, these systems do not often provide guidance on the need for dose modification. It appears that current medical training has deficiencies in the area of renal dosing and thus potentially negatively impacts patient safety. With the shortage of nephrologists and the growing CKD population, it is essential that IM house-staff receive more nephrology clinical exposure and formal didactic educational training during residency to better manage the complex treatment regimens and minimize morbidity due to medication dosing errors. Future research should focus on approaches to improve awareness and knowledge of medication use in patients with CKD as adequate adjustment of the dosage is an absolute requirement for appropriate and safe prescribing.

\section{Abbreviations}

ACGME: Accreditation Council for Graduate Medical Education: ANCOVA: Analysis of covariance; ANOVA: Analysis of variance; CKD: Chronic kidney disease; GFR: Glomerular filtration rate; IM: Internal Medicine; IMGs: International medical graduates; LSD: Least significant difference; PGY: Post-graduate year; US: United States

\section{Acknowledgements \\ We would like to thank Dr. Susan Lane MD (at Stony Brook University Hospital, Stony Brook, NY), Dr. Mark J. Corapi MD (at Winthrop University Hospital, Mineola, NY) and Dr. Steven Reichert MD (currently at St Barnabas Hospital, Bronx, NY) for allowing us to survey residents at Stony Brook University Hospital, Winthrop University Hospital and New York Hospital of Queens respectively.}

\section{Funding}

Not applicable.

\begin{abstract}
Availability of data and materials
The information supporting our findings in this study are not yet publicly available, as the data is still being analyzed for other project possibilities, but further information can be obtained from the corresponding author on reasonable request.
\end{abstract}

\section{Authors' contributions}

SS - involved in data collection and drafting the manuscript. NK - involved in data collection and literature search. AV - involved in conceiving the study, and participated in its design and acquisition of data. GS - involved in conceiving the study, and participated in its design and acquisition of data. KDJ - involved in conceiving the study and revising the manuscript critically for important intellectual content. HS - involved in conceiving the study and revising the manuscript critically for important intellectual content. DM involved in data collection and literature search. JF - made substantial contributions to analysis and interpretation of data and involved in revising the manuscript critically for important intellectual content. GS - involved in data collection and literature search. SR - conceived of the study, and participated in its design and coordination and helped to draft the manuscript. Have given final approval of the version to be published Agree to be accountable for all aspects of the work in ensuring that questions related to the accuracy or integrity of any part of the work are appropriately 
investigated and resolved. All authors read and approved the final manuscript.

\section{Competing interests}

The authors declare that they have no competing interests.

\section{Consent for publication}

Not applicable.

\section{Ethics approval and consent to participate}

The Nassau Health Care Corporation Institutional Review Board provided approval to conduct this study. All participants provided verbal informed consent. All responses were anonymous.

\section{Author details}

${ }^{1}$ Nephrology Division, Department of Medicine, Nassau University Medical Center, 2201 Hempstead Turnpike, Box 49, East Meadow, NY 11554, USA. ${ }^{2}$ Nephrology Division, Department of Medicine, North Shore University Hospital, 100 Community Dr, Manhasset, NY 11030, USA. ${ }^{3}$ Department of Business Management, Brooklyn College, 2900 Bedford Ave, Brooklyn, NY 11210, USA.

Received: 17 November 2015 Accepted: 10 January 2017

Published online: 17 January 2017

\section{References}

1. Coresh J, Selvin E, Stevens LA, Manzi J, Kusek JW, Eggers P, Van Lente F, Levey AS. Prevalence of chronic kidney disease in the United States. JAMA. 2007;298(17):2038-47.

2. Drey $\mathrm{N}$, Roderick $\mathrm{P}$, Mullee $\mathrm{M}$, Rogerson M. A population-based study of the incidence and outcomes of diagnosed chronic kidney disease. Am J Kidney Dis. 2003:42(4):677-84

3. Fox CS, Larson MG, Leip EP, Culleton B, Wilson PW, Levy D. Predictors of new-onset kidney disease in a community-based population. JAMA. 2004;291(7):844-50.

4. Coresh J, Astor BC, Greene T, Eknoyan G, Levey AS. Prevalence of chronic kidney disease and decreased kidney function in the adult US population: third national health and nutrition examination survey. Am J Kidney Dis. 2003;41(1):1-12

5. United States Renal Data System, USRDS 2014 Annual Data Report: CKD in the general population. National Institutes of Health, National Institute of Diabetes and Digestive and Kidney Diseases, Bethesda, MD, 2014

6. Plantinga LC, Crews DC, Coresh J, Miller 3rd ER, Saran R, Yee J, Hedgeman E, Pavkov M, Eberhardt MS, Williams DE, Powe NR, CDC CKD Surveillance Team. Prevalence of chronic kidney disease in US adults with undiagnosed diabetes or prediabetes. Clin J Am Soc Nephrol. 2010;5(4):673-82.

7. Garg AX, Papaioannou A, Ferko N, Campbell G, Clarke JA, Ray JG. Estimating the prevalence of renal insufficiency in seniors requiring long-term care. Kidney Int. 2004;65(2):649-53.

8. Hemmelgarn BR, Zhang J, Manns BJ, Tonelli M, Larsen E, Ghali WA, Southern DA, McLaughlin K, Mortis G, Culleton BF. Progression of kidney dysfunction in the community-dwelling elderly. Kidney Int. 2006;69(12):2155-61.

9. Manjunath G, Tighiouart H, Coresh J, Macleod B, Salem DN, Griffith JL, Levey AS, Sarnak MJ. Level of kidney function as a risk factor for cardiovascular outcomes in the elderly. Kidney Int. 2003;63(3):1121-9.

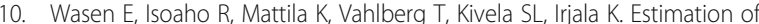
glomerular filtration rate in the elderly: a comparison of creatinine-based formulae with serum cystatin C. J Intern Med. 2004:256(1):70-8.

11. Cheeseman Day J. Population projections of the united states, by age, sex race, and hispanic origin: 1993 to 2050, current population reports. U S Bureau of the Census. 1993. p. 25-1104.

12. Stevens LA, Li S, Wang C, Huang C, Becker BN, Bomback AS, Brown WW Burrows NR, Jurkovitz CT, MCFarlane SI, Norris KC, Shlipak M, Whaley-Connell AT, Chen SC, Bakris GL, McCullough PA. Prevalence of CKD and comorbid illness in elderly patients in the united states: results from the kidney early evaluation program (KEEP). Am J Kidney Dis. 2010;55(3 Suppl 2):S23-33.

13. James MT, Laupland KB, Tonelli M, Manns BJ, Culleton BF, Hemmelgarn BR, Alberta Kidney Disease Network. Risk of bloodstream infection in patients with chronic kidney disease not treated with dialysis. Arch Intern Med. 2008; 168(21):2333-9.
14. Wong G, Hayen A, Chapman JR, Webster AC, Wang JJ, Mitchell P, Craig JC. Association of CKD and cancer risk in older people. J Am Soc Nephrol. 2009; 20(6):1341-50

15. Bolton WK. Connecting the dots: caring for the patient with progressive CKD. Nephrol News Issues. 2003;17(6):23-8.

16. Arora P, Obrador GT, Ruthazer R, Kausz AT, Meyer KB, Jenuleson CS, Pereira BJ. Prevalence, predictors, and consequences of late nephrology referral at a tertiary care center. J Am Soc Nephrol. 1999;10(6):1281-6.

17. Rifkin DE, Winkelmayer WC. Medication issues in older individuals with CKD. Adv Chronic Kidney Dis. 2010;17(4):320-8.

18. Blix HS, Viktil KK, Moger TA, Reikvam A. Use of renal risk drugs in hospitalized patients with impaired renal function-an underestimated problem? Nephrol Dial Transplant. 2006:21(11):3164-71.

19. Long CL, Raebel MA, Price DW, Magid DJ. Compliance with dosing guidelines in patients with chronic kidney disease. Ann Pharmacother. 2004 38(5):853-8

20. Manley HJ, Cannella CA, Bailie GR, St Peter WL. Medication-related problems in ambulatory hemodialysis patients: a pooled analysis. Am J Kidney Dis. 2005:46(4):669-80.

21. Manley HJ, Drayer DK, Muther RS. Medication-related problem type and appearance rate in ambulatory hemodialysis patients. BMC Nephrol. 2003:4:10.

22. Spinewine A, Schmader KE, Barber N, Hughes C, Lapane KL, Swine C, Hanlon JT. Appropriate prescribing in elderly people: how well can it be measured and optimized? Lancet. 2007;370(9582):173-84.

23. Bergman A, Olsson J, Carlsten A, Waern M, Fastbom J. Evaluation of the quality of drug therapy among elderly patients in nursing homes. Scand $J$ Prim Health Care. 2007;25(1):9-14.

24. Qato DM, Alexander GC, Conti RM, Johnson M, Schumm P, Lindau ST. Use of prescription and over-the-counter medications and dietary supplements among older adults in the United States. JAMA. 2008:300(24):2867-78.

25. Schuler J, Duckelmann C, Beindl W, Prinz E, Michalski T, Pichler M. Polypharmacy and inappropriate prescribing in elderly internal-medicine patients in Austria. Wien Klin Wochenschr. 2008;120(23-24):733-41.

26. Bailie GR, Eisele G, Liu L, Roys E, Kiser M, Finkelstein F, Wolfe R, Port F, Burrows-Hudson S, Saran R. Patterns of medication use in the RRI-CKD study: focus on medications with cardiovascular effects. Nephrol Dial Transplant. 2005;20(6):1110-5

27. Farag A, Garg AX, Li L, Jain AK. Dosing errors in prescribed antibiotics for older persons with CKD: a retrospective time series analysis. Am J Kidney Dis. 2014;63(3):422-8.

28. Hassan Y, Al-Ramahi R, Abd Aziz N, Ghazali R. Drug use and dosing in chronic kidney disease. Ann Acad Med Singapore. 2009;38(12):1095-103.

29. Lazarou J, Pomeranz BH, Corey PN. Incidence of adverse drug reactions in hospitalized patients: a meta-analysis of prospective studies. JAMA. 1998; 279(15):1200-5.

30. Rosenbloom D, Wynne C. Detecting adverse drug reactions. CMAJ. 1999; 161(3):247-8.

31. Bates DW, Su L, Yu DT, Chertow GM, Seger DL, Gomes DR, Dasbach EJ, Platt R. Mortality and costs of acute renal failure associated with amphotericin B therapy. Clin Infect Dis. 2001;32(5):686-93.

32. Ernst FR, Grizzle AJ. Drug-related morbidity and mortality: updating the cost-of-illness model. J Am Pharm Assoc (Wash). 2001;41(2):192-9.

33. American Society of Consultant Pharmacists. Seniors at risk: designing the system to protect America's most vulnerable citizens from medication related problems. 2004

34. Parker MG, Ibrahim $T$, Shaffer $R$, Rosner $M H$, Molitoris BA. The future nephrology workforce: will there be one? Clin J Am Soc Nephrol. 2011;6(6):1501-6.

35. Go AS, Chertow GM, Fan D, McCulloch CE, Hsu CY. Chronic kidney disease and the risks of death, cardiovascular events, and hospitalization. N Engl J Med. 2004;351(13):1296-305

36. McClellan WM, Resnick B, Lei L, Bradbury BD, Sciarra A, Kewalramani R, Ouslander JG. Prevalence and severity of chronic kidney disease and anemia in the nursing home population. J Am Med Dir Assoc. 2010;11(1):33-41.

37. Physicians' Desk Reference, 67th edition. Montvale: PDR Network, LLC; 2012.

38. Drug Information. UpToDate. http://www.uptodate.com. Accessed 9 Oct 2014

39. Nasca TJ, Philibert I, Brigham T, Flynn TC. The next GME accreditation system-rationale and benefits. N Engl J Med. 2012;366(11):1051-6.

40. Mark TL, Levit KR, Buck JA. Datapoints: psychotropic drug prescriptions by medical specialty. Psychiatr Serv. 2009;60(9):1167. 
41. Goodwin R, Gould MS, Blanco C, Olfson M. Prescription of psychotropic medications to youths in office-based practice. Psychiatr Serv. 2001;52(8):1081-7.

42. Hohmann AA, Larson DB, Thompson JW, Beardsley RS. Psychotropic medication prescription in U.S. ambulatory medical care. DICP. 1991;25(1):85-9.

43. Small GW. Psychopharmacological treatment of elderly demented patients. J Clin Psychiatry. 1988;49(Suppl):8-13.

44. Katon W, von Korff M, Lin E, Bush T, Ormel J. Adequacy and duration of antidepressant treatment in primary care. Med Care. 1992;30(1):67-76.

45. Cole S, Raju M, Barrett J, Gerrity M, Dietrich A. The MacArthur foundation depression education program for primary care physicians: background and rationale. Gen Hosp Psychiatry. 2000;22(5):299-358.

46. Eisenberg $L$. Treating depression and anxiety in primary care. Closing the gap between knowledge and practice. N Engl J Med. 1992;326(16):1080-4.

47. Kroenke K, Taylor-Vaisey A, Dietrich AJ, Oxman TE. Interventions to improve provider diagnosis and treatment of mental disorders in primary care. A critical review of the literature. Psychosomatics. 2000;41(1):39-52.

48. Schurman RA, Kramer PD, Mitchell JB. The hidden mental health network. treatment of mental illness by nonpsychiatrist physicians. Arch Gen Psychiatry. 1985;42(1):89-94.

49. Centers for Disease Control and Prevention. National vital stats report Deaths: preliminary data for 2011. 2012;61 (6):1-51.

50. Pfuntner A, Wier L, Stocks C. Most frequent conditions in U.S. hospitals, 2010. HCUP Statistical Brief \#148 2013 Jan. Rockville: Agency for Healthcare Research and Quality; 2010

51. Centers for Medicare \& Medicaid Services (CMS) and the Joint Commission. Specifications manual for national hospital inpatient quality measure. 2015.

52. Hetterich N, Lauterbach E, Sturer A, Weilemann LS, Lauterbach M. Toxicity of antihypertensives in unintentional poisoning of young children. J Emerg Med. 2014;47(2):155-62.

53. Thurston MM, Phillips BB, Bourg CA. Safety and efficacy of allopurinol in chronic kidney disease. Ann Pharmacother. 2013;47(11):1507-16.

54. Wallace SL, Omokoku B, Ertel NH. Colchicine plasma levels. Implications as to pharmacology and mechanism of action. Am J Med. 1970;48(4):443-8.

55. Baud FJ, Sabouraud A, Vicaut E, Taboulet P, Lang J, Bismuth C, Rouzioux JM, Scherrmann JM. Brief report: treatment of severe colchicine overdose with colchicine-specific fab fragments. N Engl J Med. 1995;332(10):642-5.

56. Kuncl RW, Duncan G, Watson D, Alderson K, Rogawski MA, Peper M. Colchicine myopathy and neuropathy. N Engl J Med. 1987;316(25):1562-8.

57. Accreditation Council for Graduate Medical Education. ACGME data resource book academic year 2012-2013. Sep 2013.

58. Ellaway RH, Fink P, Graves L, Campbell A. Left to their own devices: medical learners' use of mobile technologies. Med Teach. 2014;36(2):130-8.

59. Bobb A, Gleason K, Husch M, Feinglass J, Yarnold PR, Noskin GA. The epidemiology of prescribing errors: the potential impact of computerized prescriber order entry. Arch Intern Med. 2004;164(7):785-92.

60. Dean B, Schachter M, Vincent C, Barber N. Prescribing errors in hospital inpatients: their incidence and clinical significance. Qual Saf Health Care. 2002:11(4):340-4.

\section{Submit your next manuscript to BioMed Central and we will help you at every step:}

- We accept pre-submission inquiries

- Our selector tool helps you to find the most relevant journal

- We provide round the clock customer support

- Convenient online submission

- Thorough peer review

- Inclusion in PubMed and all major indexing services

- Maximum visibility for your research

Submit your manuscript at www.biomedcentral.com/submit

CBiomed Central 